\section{Світлана Криштанович,}

кандидат наук з державного управління, доцент, доцент кафедри економіки та менеджменту Львівського державного університету фізичної культури імені Івана Боберського (м. Львів, Україна)

\section{Svitlana Kryshtanovych,}

Associate Professor of the Department

of Economics and Management, PhD of Public Administration, Associate Professor, Lviv State University of Physical Culture named after Ivan Bobersky (Lviv, Ukraine) skrischtanovich@gmail.com ORCID ID 0000-0002-2147-9028

\title{
ПЕДАГОГІЧНИЙ ЕКСПЕРИМЕНТ ФОРМУВАННЯ ПРОФЕСІИНОЇ КОМПЕТЕНТНОСТІ МАЙБУТНІХ МЕНЕДЖЕРІВ ФІЗИЧНОЇ КУЛЬТУРИ І СПОРТУ ЗА ІНФОРМАЦІЙНО-КОГНІТИВНИМ КРИТЕРІЕМ У ЗАКЛАДАХ ВИЩОЇ ОСВІТИ
}

Анотація. У статті визначено основу експериментального дослідження та встановлено методику експерименту, яка включала мету, завдання, вибір варіативних складників, обґрунтування засобів вимірювання, опис процедури експерименту та узагальнення результатів експерименту.

Для розв'язання поставлених завдань на різних етапах експериментального дослідження використано методи та методики досліджень, зокрема математичної статистики для кількісного й якісного аналізу та перевірки достовірності результатів експериментального дослідження (метод оцінки достовірності середніх величин, метод вимірювання та математичної обробки даних; t-критерій Стьюдента - для визначення наявності або відсутності статистичної розбіжності двох середніх, які подані в абсолютних значеннях). Для достовірності педагогічного експерименту було залучено магістрантів сфери знань 017 «Фізична культура і спорт» у 5-ти закладах вищої освіти України. Було виокремлено контрольну та експериментальну групи. Для розподілу груп на експериментальні та контрольні проаналізовано їхню академічну успішність за дисциплінами, які є фундаментальними для формування професійної компетентності майбутніх менеджерів фізичної культури і спорту за інформаційно-когнітивним критерієм.

Установлено, що показниками інформаційно-когнітивного критерію $€$ система знань фахових дисциплін щодо професійної підготовки та здатність використання дослідницьких умінь. Проаналізовано результати педагогічного експерименту для визначення сформованості професійної компетентності майбутніх менеджерів фізичної культури і спорту за інформаційно-когнітивним критерієм. З'ясовано, що результатом проведеного формувального етапу педагогічного експерименту є підвищення рівня сформованості професійної компетентності менеджерів фізичної культури і спорту в магістрів за інформаційно-когнітивним критерієм, що сприятиме в подальшому їхній управлінській діяльності.

Ключові слова: професійна компетентність, менеджер, фізична культура, спорт, інформаційно-когнітивний критерій, рівні сформованості.

\section{PEDAGOGICAL EXPERIMENT OF THE FORMATION OF PROFESSIONAL COMPETENCE OF FUTURE MANAGERS OF PHYSICAL CULTURE AND SPORTS, INFORMATION AND COGNITIVE CRITERIA IN INSTITUTIONS OF HIGHER EDUCATION}

Abstract. The article defines the basis of experimental research and establishes the methodology of the experiment, which included the purpose, objectives, selection of variable components, justification of measuring instruments, description of the experimental procedure and generalization of the experimental results.

To solve the problems at different stages of experimental research, research methods and techniques were used, including mathematical statistics for quantitative and qualitative analysis and verification of experimental research results: method of estimating the reliability of averages, method of measuring and mathematical data processing; Student's t-test to determine the presence or absence of statistical discrepancy between the two means, which are given in absolute values.

For the reliability of the pedagogical experiment, undergraduates in the field of knowledge 017 «Physical Culture and Sports" were involved in 5 institutions of higher education in Ukraine. The control group and the experimental group were separated. To divide the groups into experimental and control, their academic success was analyzed by disciplines that 
are fundamental for the formation of professional competence of future managers of physical culture and sports on the information and cognitive criteria.

It is established that the indicators of the information-cognitive criterion are the system of knowledge of professional disciplines on professional training and the ability to use research skills. The results of a pedagogical experiment to determine the formation of professional competence of future managers of physical culture and sports according to the informationcognitive criterion are analyzed.

During the study it was found that the result of the formative stage of the pedagogical experiment is to increase the level of professional competence of managers of physical culture and sports in masters on information and cognitive criteria, which will contribute to their future management.

Keywords: professional competence, managers, physical culture, sports, information and cognitive criteria, levels of formation.

\section{ВСТУП}

Постановка проблеми. Проведенню педагогічного експерименту відводиться особлива роль в процесі дослідження формування професійної компетентності майбутніх менеджерів з фізичної культури і спорту, оскільки в ньому перевіряються гіпотези наукового характеру, що дають змогу отримувати достовірні професійні знання, а також відпрацьовуються прийоми та методи, за допомогою яких з'ясовується рівень готовності цих фахівців до професійної діяльності. Організація педагогічного експерименту (ПЕ) розглядається як сукупність цілеспрямованих процесуальних дій суб'єктів цього процесу (науково-педагогічних працівників і магістрів) згідно з технологіями, які забезпечують аналіз стану формування професійної компетентності в майбутнього менеджера фізичної культури і спорту в закладах вищої освіти.

Аналіз наукових досліджень і публікацій. Теорія та практика процесу формування професійної компетентності фахівців передбачає загальні вимоги до виокремлення й обґрунтування її критеріїв, показників та рівнів сформованості. Цим питанням у наукових дослідженнях присвячено праці таких відомих педагогів, як І. Баклицький, С. Гончаренко, І. Зимня, В. Ортинський, Н. Фоменко, В. Ягупов та ін. Зміст цих праць дає підстави стверджувати, що сьогодні в педагогічній науці $€$ різні погляди щодо визначення критеріїв, показників та їх рівнів сформованості професійної компетентності фахівців.

\section{МЕТА І ЗАВДАННЯ ДОСЛІДЖЕННЯ}

Метою дослідження $€$ проведення та аналіз результатів педагогічного експерименту сформованості професійної компетентності майбутніх менеджерів фізичної культури і спорту за інформаційно-когнітивним критерієм у закладах вищої освіти.

\section{МЕТОДИ ДОСЛІДЖЕННЯ}

Для розв'язання поставлених завдань у статті використано методи математичної статистики для кількісного й якісного аналізу та перевірки достовірності результатів експериментального дослідження - це метод оцінки достовірності середніх величин, метод вимірювання та математичної обробки даних; t-критерій Стьюдента - для визначення наявності або відсутності статистичної розбіжності двох середніх, які подані в абсолютних значеннях.

Для реалізації формувального етапу експерименту брали участь майбутні магістри сфери знань 017 «Фізична культура і спорт» (249 магістрантів) у 5-ти закладах вищої освіти України (Дрогобицького державного педагогічного університету імені Івана Франка, Кам'янець-Подільського національного університету імені Івана Огієнка, Львівського державного університету фізичної культури імені Івана Боберського, Національного університету фізичного виховання і спорту України, Харківської державної академії фізичної культури). Було виокремлено контрольну групу (КГ) (n = 129 осіб) та експериментальну групу (ЕГ) (n=120 осіб).

\section{РЕЗУЛЬТАТИ ДОСЛІДЖЕННЯ}

Технологія проведення педагогічного експерименту передбачає послідовність взаємопов'язаних методологічних, методичних та організаційно-технічних процедур, спрямованих на отримання достовірних висновків щодо змісту формування професійної компетентності майбутніх менеджерів фізичної культури і спорту. Науковці (Глазунов А. 2003), (Дендеренко О., 2017), (Ніколаї Г., 1999), (Тверезовська Н., 2014) та інші наголошують, що встановлені загальні вимоги до проведення науково-педагогічного експерименту, зокрема: по-перше, наявність педагогічного колективу, що має готовність і бажання до експериментальної роботи та впровадження у практику інновацій; подруге, наявність гіпотези для проведення експерименту, яка має бути спрямована на отримання нового результату, що підвищуватиме ефективність освітнього процесу; по-третє, забезпечення педагогічного експерименту всім необхідним для його ефективного проведення; по-четверте, дотримання правила виконання вимог, відповідно до навчального плану та освітньої програми, а також академічної доброчесності щодо збору та інтерпретації фактів, достовірності у формулюванні висновків.

Серед основних вимог до формування програми проведення педагогічного експерименту визначають такі: теоретико-методологічна обґрунтованість; структурна повнота, зокрема наявність у програмі всіх структурних елементів; логічна послідовність усіх елементів програми; гнучкість програми.

3 метою уникнення неконтрольованих чинників на перебіг експерименту групи експериментальні та контрольні обиралися так, щоб навчання проходило паралельно, а після закінчення експерименту можна було зробити порівняльний аналіз результатів. Для розподілу груп на експериментальні та контрольні важливо було проаналізувати їхню академічну успішність за дисциплінами, які є фундаментальними для формування професійної компетентності майбутніх менеджерів фізичної культури і спорту.

Важливою умовою є вимога застосування t-критерію Стьюдента щодо нормальності розподілу досліджуваної ознаки в кожній з порівнюваних груп. Зазначимо, що t-критерій Стьюдента - це параметричний критерій, який включає у формулу розрахунки параметрів розподілу (середні арифметичні й дисперсії). За допомогою цього 
критерію встановлюється рівень статистичної значущості різниці між двома вибірками, кожна $з$ яких була представлена середнім арифметичним.

Необхідною умовою застосування t-критерію Стьюдента в проведеному нами педагогічному експерименті $€$ вимога достовірності розподілу досліджуваної ознаки в кожній з порівнюваних груп. Тому кожного разу під час проведення експерименту перевіряли, чи підпорядковані вибірки відповідають обґрунтованим вимогам педагогічного експерименту.

Проаналізуємо результати проведеного формувального етапу педагогічного експерименту сформованості професійної компетентності майбутніх менеджерів фізичної культури і спорту за інформаційно-когнітивним критерієм.

Інформаційно-когнітивний критерій сформованості професійної компетентності майбутніх менеджерів фізичної культури і спорту відтворює рівень теоретичної підготованості магістрів з циклу фахових дисциплін, засвоєння цих знань; володіння системою знань (правових, документознавчих, управлінських, психолого-педагогічних, методичних, комунікативних, інформаційно-технологічних, аналітико-статистичних тощо), необхідних для ефективного виконання професійних завдань; володіння дослідницькими знаннями, які розкривають розуміння сутності, змісту, цілей та завдань професійної діяльності.

Отже, показниками інформаційно-когнітивного критерію є система знань фахових дисциплін щодо професійної підготовки та здатність використання дослідницьких умінь.

Високий рівень сформованості професійної компетентності майбутніх менеджерів фізичної культури і спорту за інформаційно-когнітивним критерієм характеризується наявністю ґрунтовної теоретичної підготованості магістрів 3 циклу фахових дисциплін, засвоєнням цих знань, умінням виконувати професійно-орієнтовані завдання; оперування системою знань (правових, документознавчих, управлінських, психолого-педагогічних, методичних, комунікативних, інформаційно-технологічних, аналітико-статистичних), необхідних для ефективного виконання професійних завдань; яскраво виражена здатність дослідницьких знань, які розкривають розуміння сутності, змісту, цілей та завдань професійної діяльності.

Середній рівень сформованості професійної компетентності майбутніх менеджерів фізичної культури і спорту за інформаційно-когнітивним критерієм характеризується наявністю теоретичної підготованості магістрів 3 циклу фахових дисциплін, засвоєння цих знань, умінням виконувати професійно-орієнтовані завдання; помірним володінням системою знань (правових, документознавчих, управлінських, психолого-педагогічних, методичних, комунікативних, інформаційно-технологічних, аналітико-статистичних), необхідних для ефективного виконання професійних завдань; помірною здатністю щодо дослідницьких знань, які розкривають розуміння сутності, змісту, цілей та завдань професійної діяльності.

Низький рівень сформованості професійної компетентності майбутніх менеджерів фізичної культури і спорту за інформаційно-когнітивним критерієм характеризується фрагментарністю теоретичної підготованості магістрів з циклу фахових дисциплін, засвоєння цих знань, умінням виконувати професійно-орієнтовані завдання; незацікавленість щодо засвоєння системи знань (правових, документознавчих, управлінських, психолого-педагогічних, методичних, комунікативних, інформаційно-технологічних, аналітико-статистичних), необхідних для ефективного виконання професійних завдань; відсутні дослідницькі знання, які розкривають розуміння сутності, змісту, цілей та завдань професійної діяльності.

У таблиці 1 представлено показники, які характеризують сформованість професійної компетентності менеджерів фізичної культури і спорту в магістрів контрольної та експериментальної груп за інформаційно-когнітивним критерієм до проведення педагогічного експерименту.

Показники, що характеризують сформованість професійної компетентності менеджерів фізичної культури і спорту в магістрів контрольної та експериментальної груп до педагогічного експерименту за інформаційно-когнітивним критерієм (бали)

\begin{tabular}{|c|c|c|c|c|c|c|c|c|c|}
\hline \multirow[b]{2}{*}{ 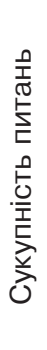 } & \multicolumn{3}{|c|}{$\begin{array}{l}\text { Кількість магістрів контрольних } \\
\text { груп, } \mathrm{n}=129\end{array}$} & \multicolumn{3}{|c|}{$\begin{array}{c}\text { Кількість магістрів } \\
\text { експериментальних груп, n=120 }\end{array}$} & \multirow[b]{2}{*}{ 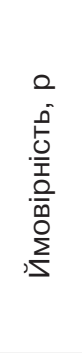 } & \multirow[b]{2}{*}{$\mathrm{t}_{\text {роз. }}$} & \multirow[b]{2}{*}{$t_{\text {Teop. }}$} \\
\hline & 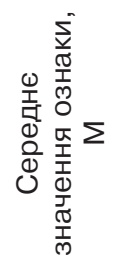 & 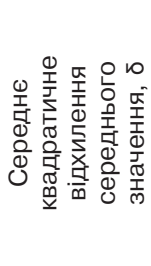 & 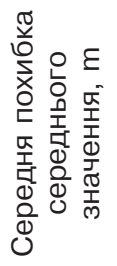 & 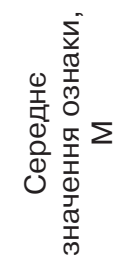 & 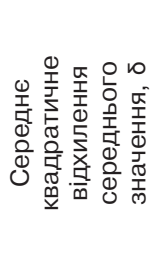 & 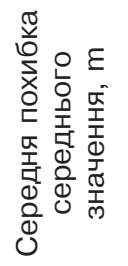 & & & \\
\hline 1 & 23,65 & 9,69 & 0,85 & 25,06 & 10,46 & 0,95 & 0,95 & 1,10 & 1,99 \\
\hline
\end{tabular}

Компаративний аналіз засвідчує відсутність статистично достовірної відмінності між середніми значеннями показників, які характеризують сформованість професійної компетентності менеджерів фізичної культури і спорту в магістрів контрольної та експериментальної груп до проведення педагогічного експерименту. Тому можемо зробити висновок, що контрольна та експериментальна групи були однорідними за своїм складом (при $\mathrm{t}$ роз. = 1,10).

У таблиці 2 відтворено зміни, що відбулися в показниках, які характеризують сформованість професійної компетентності менеджерів фізичної культури і спорту в магістрів контрольної та експериментальної груп у процесі проведення педагогічного експерименту. 


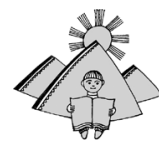

Таблиця 2

Динаміка показників, які характеризують сформованість професійної компетентності менеджерів фізичної культури і спорту в магістрів контрольної та експериментальної груп за інформаційно-когнітивним критерієм (бали)

\begin{tabular}{|c|c|c|c|c|c|c|c|c|c|}
\hline \multirow{2}{*}{$\begin{array}{c}\text { № } \\
\Pi / \Pi\end{array}$} & \multicolumn{2}{|c|}{$\begin{array}{c}\text { Середнє } \\
\text { значення } \\
\text { показника «O», } \\
\text { бали }\end{array}$} & \multicolumn{2}{|c|}{$\begin{array}{c}\text { Середнє } \\
\text { квадратичне } \\
\text { відхилення } \\
\text { середнього } \\
\text { значення } \\
\text { показника «О» }\end{array}$} & \multicolumn{2}{|c|}{$\begin{array}{c}\text { Середня } \\
\text { похибка } \\
\text { середнього } \\
\text { значення } \\
\text { показника «O» }\end{array}$} & \multirow{2}{*}{ 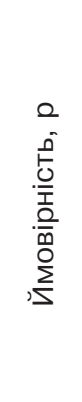 } & \multirow{2}{*}{$t_{\text {роз. }}$} & \multirow{2}{*}{$\mathrm{t}_{\text {теop. }}$} \\
\hline & 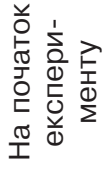 & 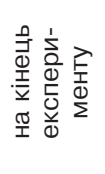 & 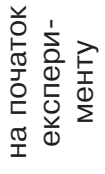 & 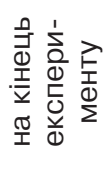 & 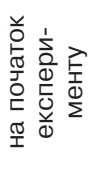 & 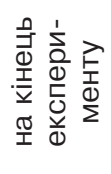 & & & \\
\hline 1 & \multicolumn{9}{|c|}{ Контрольна група, n=129 } \\
\hline 2 & 23,65 & 25,60 & 9,69 & 9,89 & 0,85 & 0,87 & 0,95 & 1,57 & 1,99 \\
\hline 3 & \multicolumn{9}{|c|}{ Експериментальна група, n=120 } \\
\hline 4 & 25,06 & 30,38 & 10,46 & 9,42 & 0,95 & 0,86 & 0,95 & 4,21 & 1,99 \\
\hline
\end{tabular}

Наприкінці формувального етапу педагогічного експерименту середні значення показників, які характеризують сформованість професійної компетентності менеджерів фізичної культури і спорту в магістрів контрольної групи, збільшилися з 23,65 \pm 0,85 до 25,60 \pm 0,87 балів, у магістрів експериментальної групи - відповідно з 25,06 \pm 0,95 до 30,38 \pm 0,86 балів. При цьому виявлено відмінність між показниками $(25,60 \pm 0,87)$, які характеризують сформованість професійної компетентності менеджерів фізичної культури і спорту в магістрів контрольної групи, і показниками $(30,38 \pm 0,86)$, які характеризують сформованість професійної компетентності менеджерів фізичної культури і спорту в магістрів експериментальної групи (при tроз. =4,21).

Динаміку рівнів, які характеризують сформованість професійної компетентності менеджерів фізичної культури і спорту в магістрів контрольної та експериментальної груп, відображено в табл. 3.

Таблиця 3

Динаміка рівнів, які характеризують сформованість професійної компетентності менеджерів фізичної культури і спорту в магістрів контрольної та експериментальної груп за інформаційно-когнітивним критерієм

\begin{tabular}{|c|c|c|c|c|c|c|c|c|c|c|c|}
\hline \multirow{4}{*}{$\begin{array}{c}\text { № } \\
\Pi / \Pi\end{array}$} & \multirow{4}{*}{ 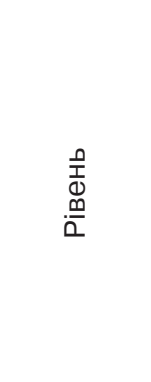 } & \multicolumn{5}{|c|}{ Контрольна група, n=129 } & \multicolumn{5}{|c|}{ Експериментальна група, n=120 } \\
\hline & & \multicolumn{10}{|c|}{ педагогічний експеримент } \\
\hline & & \multicolumn{2}{|c|}{ Початок } & \multicolumn{2}{|c|}{ Кінець } & \multirow[b]{2}{*}{ 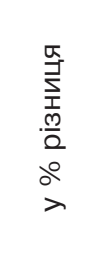 } & \multicolumn{2}{|c|}{ Початок } & \multicolumn{2}{|c|}{ Кінець } & \multirow[b]{2}{*}{ 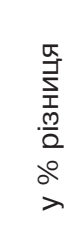 } \\
\hline & & œ & 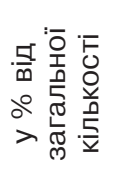 & 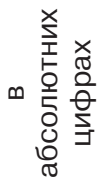 & 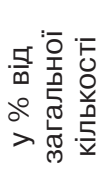 & & 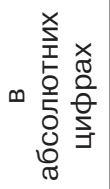 & 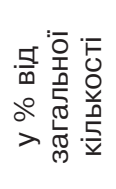 & 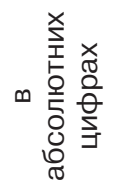 & 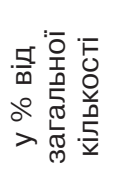 & \\
\hline 1 & Високий & 8 & 6,20 & 15 & 11,63 & 5,43 & 10 & 8,33 & 21 & 17,50 & 9,17 \\
\hline 2 & Середній & 59 & 45,74 & 70 & 54,26 & 8,53 & 58 & 48,33 & 76 & 63,33 & 15,00 \\
\hline 3 & Низький & 62 & 48,06 & 44 & 34,11 & 13,95 & 52 & 43,33 & 23 & 19,17 & 24,17 \\
\hline
\end{tabular}

На початку педагогічного експерименту високий рівень сформованості професійної компетентності менеджерів фізичної культури і спорту продемонстрували 8 магістрів контрольної групи, що становить 6,20 \%, і 10 магістрів експериментальної групи, що становить 8,33 \%; середній рівень сформованості професійної компетентності менеджерів фізичної культури і спорту продемонстрували 59 магістрів контрольної групи, що становить 45,74 \%, і 58 магістрів експериментальної групи, що становить 48,33 \%; низький рівень сформованості професійної компетентності менеджерів фізичної культури і спорту продемонстрували 62 магістрів контрольної групи, що становить 48,06 \%, і 52 магістрів експериментальної групи, що становить 43,33 \%.

На завершення педагогічного експерименту високий рівень сформованості професійної компетентності менеджерів фізичної культури і спорту засвідчили 15 магістрів контрольної групи, що становить 11,63 \%, і 21 магістрів експериментальної групи, що становить 17,50%; середній рівень сформованості професійної 
компетентності менеджерів фізичної культури і спорту продемонстрували 70 магістрів контрольної групи, що становить 54,26 \%, і 76 магістрів експериментальної групи, що становить 63,33 \%; низький рівень сформованості професійної компетентності менеджерів фізичної культури і спорту продемонстрував 44 магістрів контрольної групи, що становить 34,11 \%, і 23 магістрів експериментальної групи, що становить 19,17 \% (рис. 1).

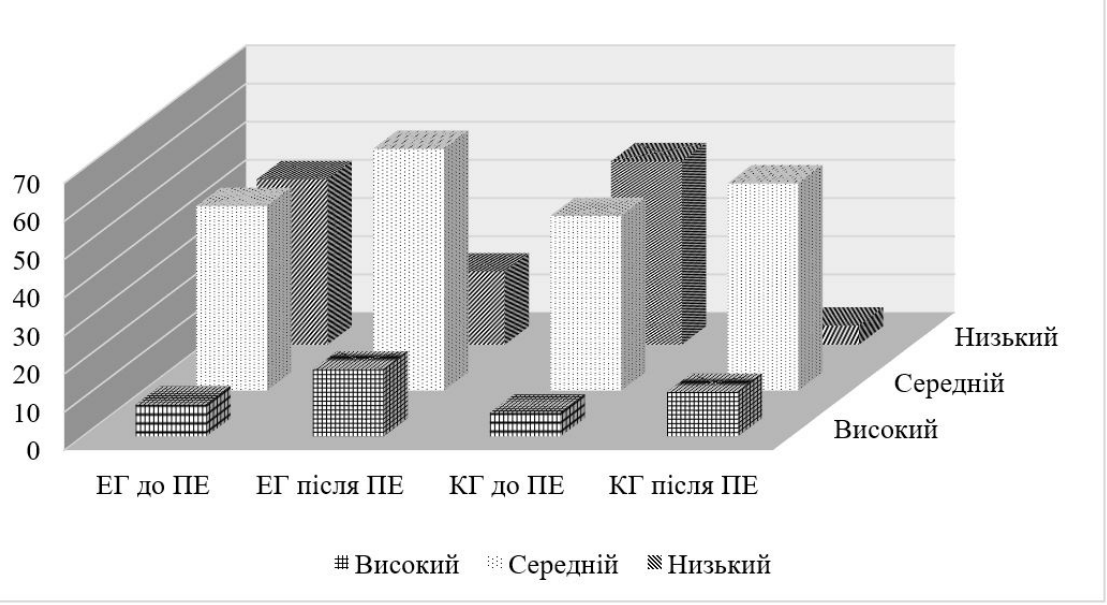

Рис. 1. Динаміка рівнів сформованості професійної компетентності менеджерів фізичної культури і спорту в магістрів контрольної та експериментальної груп, \%

Результатом проведеного формувального етапу педагогічного експерименту вважаємо підвищення рівня сформованості професійної компетентності менеджерів фізичної культури і спорту в магістрів контрольної та експериментальної груп. Підтвердженням вищезазначеної тези є збільшення в експериментальній групі на 9,17 \% кількості магістрів з високим рівнем сформованості професійної компетентності менеджерів фізичної культури і спорту порівняно зі збільшенням в контрольній групі на 5,43 \% кількості магістрів з високим рівнем сформованості професійної компетентності менеджерів фізичної культури і спорту. Також простежуємо збільшення в експериментальній групі на 15,00 \% кількість магістрів із середнім рівнем сформованості професійної компетентності менеджерів фізичної культури і спорту порівняно зі збільшенням в контрольній групі на 8,53 \% кількості магістрів з середнім рівнем сформованості професійної компетентності менеджерів фізичної культури і спорту. Позитивна динаміка спостерігалася у зменшенні в експериментальній групі на 24,17 \% кількості магістрів 3 низьким рівнем сформованості професійної компетентності менеджерів фізичної культури і спорту порівняно зі зменшенням в контрольній групі на 13,95 \% кількості магістрів з низьким рівнем сформованості професійної компетентності менеджерів фізичної культури і спорту.

\section{ВИСНОВКИ ТА ПЕРСПЕКТИВИ ПОДАЛЬШИХ ДОСЛІДЖЕНЬ}

Отже, педагогічний експеримент показав ефективність запропонованої системи формування професійної компетентності майбутніх менеджерів фізичної культури і спорту до розв'язання можливих професійних завдань за інформаційно-когнітивним критерієм.

Подальшого вивчення потребують питання сучасного навчально-методичного супроводу щодо формування професійної компетентності майбутніх фахівців у сфері менеджменту фізичної культури і спорту.

\section{СПИСОК ВИКОРИСТАНИХ ДЖЕРЕЛ}

Глазунов А.Т. (2003). Педагогические исследования: содержание, организация, обработка результатов. М.: Издательский центр АПО.

Дендеренко О.О. (2017). Організація та результати педагогічного експерименту з формування професійної компетентності майбутніх суднових механіків. Науковий часопис Національного педагогічного університету імені М. П. Драгоманова. Серія 5 : Педагогічні науки : реалії та перспективи. Київ : Вид-во НПУ ім. М. П. Драгоманова, Вип. 59. С. 40-47.

Ніколаї Г.Ю. (1999). Методологія та технологія науково-педагогічних досліджень. Суми: СДПУ ім. А.С. Макаренка.

Тверезовська Н.Т. (2014). Методологія педагогічного дослідження. Київ: Центр учбової літератури.

\section{REFERENCES}

Glazunov A.T. (2003). Pedagogicheskiye issledovaniya: soderzhaniye, organizatsiya, obrabotka rezul'tatov. M.: Izdatel'skiy tsentr APO.

Denderenko O.O. (2017). Orhanizatsiya ta rezul'taty pedahohichnoho eksperymentu z formuvannya profesiynoyi kompetentnosti maybutnikh sudnovykh mekhanikiv. Naukovyy chasopys Natsional'noho pedahohichnoho universytetu imeni M. P. Drahomanova. Seriya 5 : Pedahohichni nauky : realiyi ta perspektyvy. Kyyiv : Vyd-vo NPU im. M. P. Drahomanova, 59. 40-47.

Nikolayi H.YU. (1999). Metodolohiya ta tekhnolohiya naukovo-pedahohichnykh doslidzhen. Sumy: SDPU im. A.S. Makarenka.

Tverezovskaya, N. T. (2014). Methodology of pedagogical research. Kyiv: Center for Educational Literature. 